\title{
The Polarizability and Second Hyperpolarizability of the Phenyl Cation
}

\author{
M. G. Papadopoulos and J. Waite \\ National Hellenic Research Foundation, 48, Vas. Constantinou Ave., \\ GR-116 35 Athenes, Greece
}

Z. Naturforsch. 40 a, 1140-1142 (1985); received September 2, 1985

\begin{abstract}
The polarizability, $\alpha$, and second hyperpolarizability, $\gamma$, of the phenyl cation are computed by employing the $\mathrm{CHF}-\mathrm{PT}-\mathrm{EB}-\mathrm{CNDO}$ method. Variations of the properties induced by changes
\end{abstract} in the structure of the cation are discussed.

\section{Introduction}

The phenyl cation has been the subject of special interest since 1942, when it was proposed as an intermediate in the decomposition of the benzene diazonium ion [1-5].

The objective of this communication is to discuss the change in the polarizability, $\alpha[6]$, and second hyperpolarizability, $\gamma$ [6] of $\mathrm{C}_{6} \mathrm{H}_{5}^{+}$, resulting from geometry variations of this cation. In addition these variations are related to the stability of $\mathrm{C}_{6} \mathrm{H}_{5}^{+}$.

The present study is considered timely and of current interest because:

(a) Very little is known concerning the electric moments (permanent and induced) of molecular cations [7].

(b) Questions related to the potential importance of environmental factors on the isomerization process of the phenylium cation, as well as the properties of the ion itself have already been raised in the literature [5].

(c) The phenyl cation, due to the strong polarization of the system toward $\mathrm{C}^{+}[1]$ and the delocalization of positive charge (almost $70 \%$ of the positive charge is away from $\mathrm{C}^{+}$) [1], is a significant model system for the study of polarization phenomena in positively charged molecular species.

\section{Method}

The computation of the properties has been performed by employing the CHF-PT-EB-CNDO method [8-12]. An essential part of this technique

Reprint requests to Dr. M. G. Papadopoulos, National Hellenic Research Foundation, 48, Vas. Constantinou Ave., GR-116 35 Athens, Greece. is the optimization of the basis set with respect to some judiciously chosen experimental results. This feature allows:

(a) An effective treatment of problems related to the correlation effect, which cannot practically be dealt with by ab-initio methods (due to the size of the compounds considered here) and which are essential for the accurate determination of $\alpha$ and in particular $\gamma[13]$.

(b) The best use to be made of available information in order to extend it to other related molecules and/or properties.

The basis set employed for the study of $\mathrm{C}_{6} \mathrm{H}_{5}^{+}$ has been optimized with respect to benzene [14] (Table 1, footnote c) due to lack of any experimental data for the polarizability and hyperpolarizabilty of molecular cations. This facilitates the systematic comparison between the properties of charged species (both positive and negative [14]) with those of their neutral precursor, although it is understandable that the wave function may be less successful for the charged species than it has been for $\mathrm{C}_{6} \mathrm{H}_{6}$. However, this possible shortcoming is circumvented by concentrating on the study of differences of properties and in the identification of trends. Thus it is considered that the reported analysis retains its validity although the absolute values may be revised.

\section{Results and Discussion}

It is observed (Table 1) that the results from the phenyl cation confirm the trend which has already been found [15], according to which molecular positive ions have $\alpha$ and $\gamma$ values smaller, in general, than the values of their neutral precursors and within the same order of magnitude as them. 
Table 1. The polarizability, $\alpha^{\mathrm{a}}$, and second hyperpolarizability, $\gamma^{\text {b }}$ of $\mathrm{C}_{6} \mathrm{H}_{5}^{+}$and its neutral precursor, $\mathrm{C}_{6} \mathrm{H}_{6}$.

\begin{tabular}{|c|c|c|c|c|c|}
\hline Cation & $\alpha^{\mathrm{c}}$ & $y^{c}$ & $\begin{array}{l}\text { Neutral } \\
\text { precursor }\end{array}$ & $\alpha$ & $\gamma$ \\
\hline $\begin{array}{r}\mathrm{C}_{6} \mathrm{H}_{5}^{+}, \frac{\mathrm{d}}{\mathrm{e}} \\
\mathrm{f} \\
\mathrm{g} \\
\mathrm{h}\end{array}$ & $\begin{array}{l}60.8 \\
56.5 \\
56.5 \\
54.7 \\
58.0\end{array}$ & $\begin{array}{l}12800 \\
14500 \\
13900 \\
12200 \\
14100\end{array}$ & $\mathrm{C}_{6} \mathrm{H}_{6}$ & $\begin{array}{l}68.3[14] \\
61.9[10] \\
62.1[18] \\
51.9[19] \\
66.8^{i}[20] \\
69.5^{\mathrm{i}}[21]\end{array}$ & $\begin{array}{l}22300[14] \\
24700[10] \\
73300[22] \\
13500[23] \\
24500 \\
\pm 596^{\mathrm{i}}[24] \\
18600 \\
\pm 2780^{\mathrm{i}}[25]\end{array}$ \\
\hline
\end{tabular}

a In a.u., 1 a.u. of polarizability $\cong 0.148176 \times 10^{-24} \mathrm{esu}$ $\cong 0.164867 \times 10^{-40} \mathrm{C}^{2} \mathrm{~m}^{2} \mathrm{~J}^{-1}$.

b In a.u., 1 a.u. of hyperpolarizability $\cong 0.503717 \times 10^{-39}$ $\mathrm{esu} \cong 0.623597 \times 10^{-64} \mathrm{C}^{4} \mathrm{~m}^{4} \mathrm{~J}^{-3}$

c The computations have been performed by employing the following basis [14]:

C: $2 \mathrm{~s}(1.625), 2 \mathrm{p}(1.625)$;

$\mathrm{H}: 1 \mathrm{~s}(0.9), 2 \mathrm{~s}(0.4223), 2 \mathrm{p}(0.4223)$.

d The geometry is from [2]. The structure is presented in Fig. 1 (1).

e The geometry is from [2]. The structure is presented in Fig. 1 (2). It has $\mathrm{C}_{2 \mathrm{v}}$ symmetry.

f The $\mathrm{C}_{1} \mathrm{HC}_{2}$ plane (this plane involves the $\mathrm{H}$ which migrates) forms a $45^{\circ}$ angle with the plane of the other atoms.

$\mathrm{g}$ The $\mathrm{C}_{1} \mathrm{HC}_{2}$ plane (see footnote f) forms a $90^{\circ}$ angle with the plane of the other atoms.

$\mathrm{h}$ The computations have been performed by employing the geometric model of the neutral precursor [10].

$i$ This value has been determined experimentally.
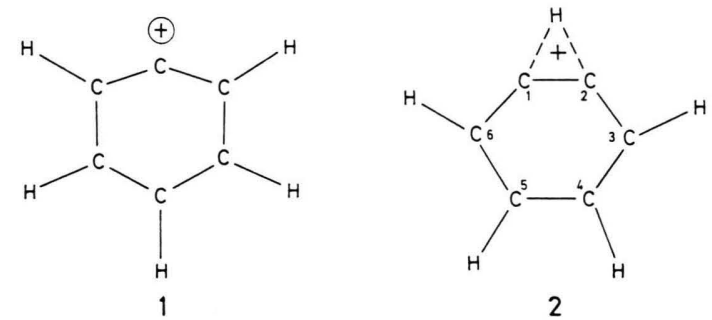

Fig. 1. Structure of the cations that have been considered.

Employing for the phenyl cation (Fig. 1), the geometry given by Schleyer et al. [2] (this was fully optimized with a split valence basis set, $3-21 \mathrm{G} / / 3$ $21 \mathrm{G})$ and the experimental bond angles and lengths of benzene [10], we find that the differences in $\alpha$ and $\gamma$ are 2.8 a.u. and 1300 a.u., respectively (Table 1). The optimized geometry is associated with higher polarizability and lower hyperpolarizability compared to the values given by using the geometry of the neutral precursor [10].

It has been found that the difference in energy between $\mathbf{1}$ and $\mathbf{2}$ (which is indicated to be a transition structure in the automerization of the phenylium ion [2]) is $67.2 \mathrm{kcal} \mathrm{mol}^{-1}$ and $52.2 \mathrm{kcal}$. $\mathrm{mol}^{-1}$ at 3-21G//3-21G and MP2/6-31G**//3-21G, respectively [2]. The present results show that the differences in $\alpha$ and $\gamma$ between $\mathbf{1}$ and 2 are 4.3 a.u. and 1700 a.u., respectively (Table 1 ).

It is observed that the transition state (2) has lower $\alpha$ and higher $\gamma$ with respect to 1 . To get a feeling of what these differences mean, in terms of energy, we employ an approximate field of $10^{6}$ esu (Buckingham [16a] considers that this is approximately the value of the field which is found at a point a few Angstrom units from an ion or polar molecule), and find that the non-linear inductive effect [16b], associated with $\alpha$ and $\gamma$, leads to a destabilization of $\mathbf{2}$ in comparison to $\mathbf{1}$ of approximately $4 \mathrm{kcal} \mathrm{mol}^{-1}$.

It is noted that $\gamma$ is a uniquely sensitive probe of intramolecular changes. As an example it is observed that the difference in energy between $\mathbf{1}$ and $\mathbf{2}$ (at the $3-21 \mathrm{G} / / 3-21 \mathrm{G}$ level, empolying 1 as a reference), is $0.05 \%$ [2], while the difference in $\gamma$ is $13.3 \%$

In order to increase our understanding of the transition structure, and since Schleyer et al. [2] believe that this structure has a $\mathrm{C}_{\mathrm{s}}$ symmetry, we have performed computations on another two configurations; that is when the plane, which is defined by the hydrogen which migrates and $\mathrm{C}_{1}$ and $\mathrm{C}_{2}$ (Fig. 1) forms angles of $45^{\circ}$ and $90^{\circ}$ with the ring plane. We see that the difference in $\alpha$ is small and is observed when the angle gets larger than $45^{\circ}$.

The geometry variations in the phenyl cation, which have been considered, produce changes less than $10 \%$ for $\alpha$ and $15 \%$ for $\gamma$ (employing as a reference point the values for $\mathbf{1}$ ).

It is useful to note that work which is currently in progress shows that the hyperpolarizability of $1-\mathrm{C}_{14} \mathrm{H}_{9}^{+}$(ion of anthracene) appears to change considerably as a function of the geometry. Thus, employing the symmetric geometry of the neutral precursor, $\gamma$ equals 136000 a.u. [15] while for the complete MNDO [17] optimized geometry of the ion we find $\gamma$ has the value 79500 a.u. On the other hand, the $\gamma$ value of $4-\mathrm{C}_{14} \mathrm{H}_{9}^{+}$(ion of phenanthrene) employing the symmetric geometry is 92500 a.u.

The results for the phenyl cation and $\mathrm{C}_{14} \mathrm{H}_{9}^{+}$show that the structure-polarization relationship of molecular cations needs to be studied in much greater detail before conclusive rules can be stated. 
[1] J. D. Dill, R. v. R. Schleyer, J. S. Binkley, R. Seeger, J. A. Pople, and E. Haselbach, J. Amer. Chem. Soc. 98, 5428 (1976).

[2] R. v. R. Schleyer, A. J. Kos, and K. Raghavachari, Chem. Commun. 1983, 1296.

[3] E. M. Evleth and P. M. Horowitz, J. Amer. Chem. Soc. 93, 5636 (1971). - C. G. Swain, J. E. Sheats, D. G. Gorenstein, and K. G. Harbison, J. Amer. Chem. Soc. 97, 791 (1975). - H. H. Jaffé and G. F. Koser, J. Org. Chem. 40, 3082 (1975).

[4] M. Speranza, Y. Keheyan, and G. Angelini, J. Amer. Chem. Soc. 105, 6377 (1983). - M. Speranza, M. D. Sefcik, J. M. S. Henis, and P. P. Gaspar, J. Amer. Chem. Soc. 99, 5583 (1977). - M. Speranza, Tetrahedron Lett. 21, 1983 (1980).

[5] G. Angelini, S. Fornarini, and M. Speranza, J. Amer. Chem. Soc. 104, 4773 (1982)

[6] a) The average polarizability and second hyperpolarizability $\gamma$ are given by [6b]

$\alpha=\frac{1}{3}\left(\alpha_{x x}+\alpha_{y y}+\alpha_{z z}\right)$,

$\gamma=\frac{1}{5}\left(\gamma_{x x x x}+\gamma_{y y y y}+\gamma_{z z z z}+2 \gamma_{x x y y}+2 \gamma_{x x z z}+2 \gamma_{y y z z}\right)$, where $x, y$ and $z$ define Cartesian components. Expressions for the relevant tensor components, in terms of which $\alpha$ and $\gamma$ are defined, are given in [6c].

b) A. D. Buckingham and B. J. Orr, Q. Rev. Chem. Soc. 21, 195 (1967).

c) R. McWeeny, Phys. Rev. 126, 1028 (1962). G. Diercksen and R. McWeeny, J. Chem. Phys. 44, 3554 (1966). - J. L. Dodds, R. McWeeny, W. T. Raynes, and J. P. Riley, Mol. Phys. 33, 611 (1977).

[7] Notable examples of the very few articles concerning the polarizability of molecular cations are: F. T. Marchese and H. H. Jaffé, J. Mol. Struct. Theochem. 86, 97 (1981). - A. Hinchliffe, R. W. Munn, and W. Siebrand, J. Phys. Chem. 87, 3837 (1983).

[8] C. A. Nicolaides, M. G. Papadopoulos, and J. Waite, Theor. Chim. Acta 61, 427 (1982).
[9] M. G. Papadopoulos, J. Waite, and C. A. Nicolaides, J. Chem. Phys. 77, 2527 (1982).

[10] J. Waite, M. G. Papadopoulos, and C. A. Nicolaides, J. Chem. Phys. 77, 2536 (1982).

[11] J. Waite and M. G. Papadopoulos, J. Chem. Phys. 82, 1427 (1985).

[12] J. Waite and M. G. Papadopoulos, J. Chem. Soc. Faraday Trans. II, 81, 433 (1985).

[13] R. J. Bartlett and G. D. Purvis III, Phys. Rev. A, 20, 1313 (1979). - G. D. Purvis III, and R. J. Bartlett, Phys. Rev. A 23, 1594 (1981).

[14] J. Waite and M. G. Papadopoulos, J. Comp. Chem. 4, 578 (1983).

[15] J. Waite and M. G. Papadopoulos, J. Phys. Chem. 89, 2291 (1985).

[16] a) A. D. Buckingham, Q. Rev. Chem. Soc. 13, 183 (1959).

b) P. W. Langhoff, J. D. Lyons, and R. P. Hurst, Phys. Rev. 148, 18 (1966).

[17] M. J. S. Dewar and W. Thiel, The MNDO program from QCPE 353. The optimized coordinates of $1-\mathrm{C}_{14} \mathrm{H}_{9}^{+}$cation are available on request.

[18] F. T. Marchese and H. H. Jaffé, Theor. Chim. Acta 45, 241 (1977).

[19] R. Mathies and A. C. Albrecht, J. Chem. Phys. 60, 2500 (1974)

[20] R. J. W. Lefévre and K. M. S. Sundaram, J. Chem. Soc. B, 1963, 4442 .

[21] M. P. Bogaard, A. D. Buckingham, M. G. Corfield, D. A. Dunmur, and A. H. White, Chem. Phys. Lett. 12, 558 (1972).

[22] E. N. Svendsen, T. Stroyer-Hansen, and H. F. Hameka, Chem. Phys. Lett. 54, 217 (1978).

[23] O. Zamani-Khamiri, E. F. McIntyre, and H. F. Hameka, J. Chem. Phys. 72, 1280 (1980).

[24] J. F. Ward and D. S. Elliott, J. Chem. Phys. 69, 5438 (1978).

[25] B. F. Levine and C. G. Bethea, J. Chem. Phys. 63, 2666 (1975). 